Гуманитарные ведомости ТГПУ им. Л. Н. Толстого № 2 (34), октябрь 2020 г.

В. А. Баркалов

Воронеж ский государственнный университет

\title{
КУЛЬТУРОЛОГИЧЕСКИЙ АНАЛИЗ ДЕЯТЕЛЬНОСТИ ВОЛЬНЫХ ПОЖАРНЫХ ДРУЖИН (НА ПРИМЕРЕ ВОРОНЕЖСКОЙ ГУБЕРНИИ)
}

В статье анализируется деятельность вольных пожарных отрядов в этикокультурологическом контексте. Автор рассматривает значение и специфику феномена добровольчества, исследует социокультурные и духовные причины создания в России вольных пожарных отрядов. Автор приходит к выводу, что деятельность этих формирований отражает основные нравственные качества русского характера: соборность, бескорыстие, самоотверженность, благородство.

Ключевые слова: вольные пожарные отряды, добровольчество, нравственность, духовная культура.

V. A. Barkalov

Voronezh State Universyty

(Voronezh, Russia)

\section{CULTURAL ANALYSIS OF ACTIVITY OF FREELY FIRE FRIENDS (ON THE EXAMPLE OF THE VORONEZH GOVERNMENT)}

The article analyzes the activities of free fire detachments in the ethical-cultural context. The author considers the significance and specificity of the phenomenon of volunteerism, explores the socio-cultural and spiritual causes of the creation of free fire detachments in Russia. The author comes to the conclusion that the activities of these formations reflect the basic moral qualities of the Russian character: spiritual community of the people.

Keywords: free fire detachments, volunteerism, morality, spiritual culture

DOI 10.22405/2304-4772-2020-1-2-66-73

Культурологический анализ бескорыстной помощи людям или группе людей отсылает исследователя к нескольким терминам: волонтер, доброволец, благотворитель, меценат, которые обладают определенными историческими, культурными и семантическими различиями. Говоря об этом феномене, имеется ввиду целенаправленная, как правило, многократная, помощь, которая отражает определенный менталитет, образ жизни, ценностные установки «благодетеля».

В XVIII-XIX веках под волонтером (фр. volontaire, от лат. voluntarius) в Европе понимался человек, который принял решение добровольно поступить на военную службу. Часто это были люди, ищущие приключений, и на Руси таких называли «охочими людьми». В России слово «волонтёр» вошло в обиход в петровскую эпоху вместе со многими другими французскими словами, и звучало оно как «волентир» или «волунтер». Однако западное слово не прижилось; везде, где шла речь о бескорыстном служении родине, стало использоваться слово «добровольчество»: «Добровольческая армия Корнилова», «30-й Уральский добровольческий танковый корпус», «ушел добровольцем на фронт», «комсомольцы-добровольцы» и т.д. 
Гуманитарные ведомости ТГПУ им. Л. Н. Толстого № 2 (34), октябрь 2020 г.

Во многом это объясняется русским менталитетом, нашедшим яркое и точное выражение в языке. В слове западного происхождения «волонтер» (желающий) подчеркивается способ участия в каком-либо деле, делается акцент на субъекте, и будто бы не является существенным, к чему и ради чего его желание прилагается.

Отечественное понятие «доброволец» гораздо шире и глубже франкоитальянского «волонтер». Этот термин состоит из двух слов- «добро» и «воля». Человек проявляет свободную волю делать добро: к семантике свободного выбора примешивается нравственная составляющая, которая, по сути, выходит на первый план: человек желает делать добро. Здесь уже подчеркивается не только воля субъекта, но и то, на что она направлена, и ради чего предназначена.

Добровольческая деятельность приобретает наибольшую значимость в культуре, если она связана с риском для жизни. И один из самых ярких примеров этому - деятельность добровольных (вольных) пожарных дружин. Несмотря на то, что Россия стала первой страной в мире, использующей для тушения пожаров воинские формирования (XVI век, стрельцы), пожаров не становилось меньше, а ущерб, наносимый ими, неуклонно возрастал [1]. Здесь, конечно, не последнюю роль сыграли деревянные дома, дощатые мостовые и т.д. Наконец, в XIX веке в России стали создаваться добровольные пожарные общества: в городе. Верхнеудинске Иркутской губернии в 1814 г. было организовано первое добровольное пожарное формирование.

Создание добровольных пожарных дружин имело серьезные социокультурные и духовные основания. Необходимо отметить, что деятельность отечественных пожарных никогда не была окружена романтическим ореолом, в отличие, например, от военной службы. Профессиональные пожарные имели в России низкий социальный статус, и на протяжении многих лет находились в тяжелом материальном и моральном положении: отряды были плохо технически оснащены, организованы, но самое главное, повседневная жизнь пожарных была крайне тяжелой. Пожарные находились на службе круглые сутки, под бдительным надзором полиции. Их быт был невыносим, его можно сравнить с бытом дешевых прачек или даже шахтеров. Приведем описания В. А. Гиляровского: «Пожарные в двух этажах, низеньких и душных, были набиты, как сельди в бочке, и спали вповалку на нарах, а кругом на веревках сушилось промокшее на пожарах платье и белье» [2, с. 35]. Добавим, тут же ютились их женщины и дети.

Эти нечеловеческие условия отнюдь не способствовали хорошему качеству их работы. Тяжелое положение пожарных служб, провоцирующее недолжное исполнение дружинниками своих обязанностей, стало одной из причин возникновения добровольческих отрядов. Впрочем, этому способствовали и властные структуры, проводившие в 1860 - 1870-гг. земскую и городскую реформы, и осуществлявшие перераспределение властных полномочий между обществом и государством. 
Добровольческая пожарная команда в г. Осташкове Тверской губернии была создана еще в 1843 году городским главой Ф. К. Савиным. Горожане, вступившие в команду, не получали никакого материального вознаграждения в течение двадцати лет, но продолжали тушить пожары. Впрочем, министерство внутренних дел России по достоинству оценило опыт Осташковской дружины, и подобная практика стала распространяться по всей территории страны.

В мае и июне 1861 года управляющий Министерством внутренних дел статс-секретарь Валуев в циркулярах, отправленных начальникам губерний, подчеркнул: «считаю не излишним присовокупить, что общественные пожарные команды могут принести действительную пользу в том случае, когда граждане сами добровольно изъявят готовность принять на себя эту повинность» [3]. И граждане охотно «принимали» эту повинность, не требуя материального награждения. С целью содействия городской пожарной команде при тушении пожаров в конце 1878 года в Воронеже по разрешению Министерства внутренних дел было создано вольное пожарное общество охотников. Как видно из архивных документов, инициаторами создания этого общества выступили некоторые гласные городской думы, ставшие в лице исполнительного органа общественного самоуправления надежными союзниками добровольцев. Такой активной бескорыстной помощи можно найти существенные объяснения.

Важно отметить, что кроме добровольцев, непосредственно тушивших пожары, приносили неоценимую пользу врачи и аптекари. Ведь вольные пожарные получали травмы, ожоги, увечья, они нуждались в медицинской помощи и финансовой поддержке. В частности, совет ВПО многократно публично выражал благодарность аптекарю Л. И. Мюфке за предоставляемые им медикаменты безвозмездно. Вместе с дружинниками к месту бедствия регулярно прибывал врач В. Н. Воищев, который также оказывал помощь на добровольных началах.

Многие исследователи отмечают особенное чувство нравственности и бескорыстия русского народа. Например, П. Е. Астафьев подчеркивает, что в этом «гипертрофированном чувстве» заключаются и великие достоинства, и недостатки, и взлеты и падения русской истории. Русский человек «ведет спустя рукава даже дело устроения своих внешних благ и средств, - не это для него важно! - бесконечно более думает о нравственном характере своих поступков... И в личную нравственность верит он всегда более, чем во всевозможные формальные гарантии...!» [4, с. 95]. Внимание к бескорыстной помощи как части духовно-онтологического ядра человеческой культуры вообще свойственно русской философско-культурной традиции. «Практически все магистральные темы русской философии концентрируются вокруг этой мега-идеи - идеи оправдания тварного бытия» [5, с. 59].

Еще одна социокультурная особенность добровольческого движения в области тушения пожаров заключается в том, что одними из самых активных организаторов и участников вольных дружин были русские предприниматели и купцы, и это не случайный феномен, а исторически сложившаяся 
Гуманитарные ведомости ТГПУ им. Л. Н. Толстого № 2 (34), октябрь 2020 г.

закономерность. С глубокой древности в нашей стране купцы были одними из самых образованных и коммуникабельных представителей общества. В этой связи можно вспомнить одну из самых древних новгородских былин, где главный герой не князь, не воин, но купец - Садко. Вероятно, не случайно взлет благотворительности имел место в России в период развития и расцвета российского предпринимательства: во второй половине XIX - начале XX вв.

Безусловно, купечество было заинтересовано и в создании квалифицированных пожарных отрядов. В России традиционно пожары наносили большой ущерб хозяйствам и городам: дерево было одним из главных строительных материалов, а в селах, при наличии деревянной утвари, большинство жителей также продолжали использовать лучины. Профессиональных пожарных команд на тот период было очень мало, и оснащены они были крайне слабо. Многие купцы не только жертвовали деньги на пожарное дело, но сами успешно руководили отрядам, участвовали в тушении пожаров, рискуя жизнью. Один из ярких примеров - добровольческая деятельность И. К. Веретенникова, почетного гражданина г. Воронежа.

Этот город со дня своего основания выгорал полностью семь раз, поэтому и вольные пожарные дружины были весьма распространенным явлением в Воронежской губернии. Веретенников происходил из купеческого рода и сам достиг в области предпринимательства значительных успехов. Он был владельцем солярного магазина, садового завода, был совладельцем крупной мельницы на реке Воронеж, конного завода, одним из учредителей Воронежского коммерческого банка. Будучи очень богатым человеком, он вкладывал огромные деньги в тушение пожаров, сам неоднократно рисковал жизнью, за что был прозван в народе «огненным чародеем» [6].

Уже с 1860-го года Иван Веретенников содержал в Воронеже частный пожарный обоз. С момента учреждения и до конца $1890-$ х гг. он успешно осуществлял руководство охотниками в команде вольного пожарного общества, неоднократно проявляя ловкость, сообразительность и героизм, за что был награжден орденом Св. Анны 3-й степени. Веретенников воплотил в себе лучшие качества российского предпринимательства, реализовав знаменитый тезис другого легендарного деятеля Павла Рябушинского «богатство обязывает».

Также на протяжении долгого времени председателем правления добровольного пожарного общества бессменно был Д. Г. Самофалов, один из самых богатых и влиятельных воронежцев того времени. Он владел в Воронеже колокольным заводом, «Вторым товариществом русских мукомолов», гостиницей «Центральная» и многим другим недвижимым имуществом. В 1879-1913 годах Д. Г. Самофалов был активным гласным городской думы, а в 1887-1891 годах занимал должность городского головы. Сам он объяснял свою гражданскую позицию как с нравственной, так и с практической точки зрения: надо жертвовать деньги и силы на деятельность добровольных пожарных дружин, чтобы максимально сократить разорительный эффект от пожаров. Тесное взаимодействие с могущественным торговцем и заводчиком лишь 
Гуманитарные ведомости ТГПУ им. Л. Н. Толстого № 2 (34), октябрь 2020 г.

укрепляло позиции Вольного пожарного общества и обеспечивало ему поддержку в решении организационных и финансовых вопросов [7].

В добровольных (вольных) пожарных обществах принимали участие разные слои населения: купцы, ремесленники, интеллигенция. Во многом активному формированию вольных пожарных обществ способствовали средства массовой информации. В частности, провинциальная печать, ставшая в пореформенный период важнейшим коммуникационным каналом, стала повсеместно поднимать вопросы плохой оснащенности городских пожарных отрядов, отсутствия должного управления и организации в них. В печати говорилось о важности создания отрядов добровольцев как необходимого явления в связи с назревшей реформой пожарной безопасности.

Так, сразу в нескольких номерах «Воронежских губернских ведомостей» за 1862 год, были опубликованы заметки Н. Милагаевича, которые спровоцировали дискуссию о формировании из среды городского общества пожарных команд [8]. Автор статьи отмечал, что, несмотря на поднятый министерством вопрос об устройстве в интересах города нового типа пожарных частей, образование добровольческих команд подвигалось медленно и во многом ошибочно. Однако журналист, критикуя процесс реформирования пожарных команд, в тоже время распространял важную информацию о намерении российского правительства взять курс на сотрудничество с обществом в решении социально значимых задач. И это определенным образом повлияло в положительном смысле на развитие частной инициативы городских жителей в сфере пожарной безопасности.

Организация и оснащение добровольческих отрядов «оставляли желать лучшего»: все держалось почти исключительно на личных качествах добровольных «бойцов», в отличие от полицейских команд, «вольные» пожарные имели в готовности только инструменты, личный же их состав собирался по тревоге в минуту необходимости. Соответственно, относительно дисциплины, внутреннего порядка и постоянной готовности к выезду на пожар вольная команда заметно проигрывала городской пожарной команде, служащие которой не имели права отлучаться из помещения команды и оставлять свой пост во время дежурства.

Далее, в вольных командах в основном имелся самый разнородный состав, в который входили люди, принадлежащие к различным классам общества, для них служение в команде, в большинстве случаев, являлось не работой, а как бы занятием «между прочим». Если вдруг среди членов вольной команды находились лица, служащие «по призванию», то и для них пожарная служба всегда оставалась делом второстепенным, ибо на первом плане стояло занятие, которое обеспечивало их существование. Нередко такой порядок приводил к тому, что команда являлась на пожар далеко не в надлежащем составе: купец находился в отлучке по своим торговым делам, ремесленник заканчивал срочную работу, студент готовился к экзамену.

Однако все недостатки организации и управления «с лихвой» компенсировались самоотверженными действиями вольных дружинников, 
Гуманитарные ведомости ТГПУ им. Л. Н. Толстого № 2 (34), октябрь 2020 г.

которые часто рисковали своей жизнью ради общего блага. Часто к дружинникам подключались все, кто оказывался поблизости. Несовершенство пожарной техники и недостаточное оснащение городских пожарных обозов делало незаменимой каждую лишнюю пару рук при тушении пожара - при подвозке воды, спасения имущества, разборке горящих зданий. И тот факт, что дисциплина все-таки оставляла желать лучшего, не умаляет героизма пожарных добровольцев. Впрочем, феномен добровольчества в дореволюционной России отличался своей спецификой, выражавшейся в крайностях: «Либо добро, либо зло, третьего не дано» [9, с. 333].

Принцип добровольности, строго соблюдавшийся при вступлении в общество, подчеркивал осознанность решения каждого его члена, повышая его авторитет в глазах общественности. Особенностью организации добровольных пожарных обществ было деление его членов на почетных, действительных и, собственно, охотников.

Звание почетных членов получали лица, которые, не вступали сами в ряды дружинников, но жертвовали в кассу общества не менее 100 рублей. При этом членские взносы поступали в запасной капитал общества, а почетные члены получали квитанцию, которая и служила доказательством вступления в эту общественную организацию. Интересно, что получить такое звание могли и женщины, что весьма показательно в контексте набиравшего тогда силу движения за «равноправие полов».

Вторая категория - действительные члены, которые обязывались вносить на нужды пожарной дружины ежегодно по 10 рублей в течение января каждого года. Но эти люди могли, при желании, и войти в состав пожарной дружины. Поскольку работа с пожарными инструментами требовала физической силы, то стать действительными членами общества могли только мужчины, причем несовершеннолетние обязаны были представить командиру дружины письменное разрешение от родителей или опекунов.

Наконец, так называемые охотники, непосредственно тушившие пожары. Никто из охотников не мог быть принуждаем к действиям, связанным с явной опасностью для жизни; в таких случаях участие добровольца определялось только его личным мужеством. Однако при этом все добровольцы во время пожара обязаны были исполнять свой долг и вести себя благородно. В случае получения охотниками на пожарах увечий или от служебных занятий - неизлечимых болезней, общество принимало на себя материальное попечение охотников, выдавая из запасного капитала каждому нуждающемуся денежное пособие.

К сожалению, несмотря на очевидную пользу, вольные пожарные отряды в Воронежской губернии не просуществовали долго. Постепенно, с 1906 года Вольное пожарное общество начало распадаться, в виду денежных затруднений прекратилась печать его ежегодных отчетов, которые до этого регулярно посылались в городскую думу и страховое общество. Его председатель, барон Сталь фон-Гольштейн, добровольно сложил с себя это звание и сдал все документы члену совета С. А. Тер-Паносову. Тот, в свою 
Гуманитарные ведомости ТГПУ им. Л. Н. Толстого № 2 (34), октябрь 2020 г.

очередь, на заседании городской думы от 27 ноября 1912 года доложил о безнадежном положении дел общества и невозможности созыва общего собрания. На заседании городской думы от 19 февраля 1916 года было принято решение о немедленной ликвидации Вольного пожарного общества в Воронежской губернии. Но деятельность пожарных добровольцев сыграла важную роль в борьбе с пожарами.

Таким образом, можно сделать вывод о том, что деятельность вольных пожарных дружин представляет собой ценный материал для исследования отечественного феномена добровольчества в культурологическом и этическом аспектах, так как воплощает в лице своих лучших представителей основные нравственные качества русского характера, альтруизм отечественных предпринимателей, интеллигенции и простых людей. В феномене пожарного добровольчества, как в капле воды, отражается этическая доминанта русской культуры. Традиционно, морально-правовые нормы отечественной культуры могут казаться неразвитыми по сравнению с так называемыми «прогрессивными» странами, но глубинные нравственные установки, как и склонность к этическим исканиям в российской культуре сильнее и ярче.

\section{Лumepamypa}

1. Жизнь и быт российских пожарных в XIX - начале XX вв. [Электронный ресурс] // Блог самарских краеведов. 2012. URL: http://www.kraeved-samara.ru (дата обращения: 16.02.2018).

2. Гиляровский В. А. Москва и москвичи. М.: АСТ, 2017. 496 с.

3. ГАВО. Ф. И-21. Оп. 1. Д. 522.

4. Астафьев П.Е. Национальность и общечеловеческие задачи (к русской народной психологии) // Вопросы философии. 1996. № 12. С. 84-102.

5. Симонова С. А.Эстетический ригоризм или социальное алиби искусства // Вестник Томского университета. Сер. Гуманитарные науки. 2008. № 310. C. 56-61.

6. ГАВО. Ф. И-21. Оп. 1. Д. 382. Л. 4.

7. ГАВО. Ф. И-21. Оп. 1. Д. 522. Л. 3 об.; 5 об.

8. ГАВО. Ф. И-21. Оп. 1. Д. 1028.

9. Симонова С. А. Особенности абсолютизации добра в русской культуре // Социально-гуманитарные знания. 2008. № 3. С. 332-339.

10. Фетисов аристократизму. Воронеж: Квадрат, 1995. 119 с.

\section{References}

1. Hizn' i byt rossijskih pozharnyh v XIX - nachale XX vv. [Life and everyday life of Russian firefighters in the XIX - early XX centuries] [Elektronnyj resurs] // Blog samarskih kraevedov. 2012. URL: http://www.kraeved-samara.ru (data obrashcheniya: 16.02.2018). [In Russian] 
Гуманитарные ведомости ТГПУ им. Л. Н. Толстого № 2 (34), октябрь 2020 г.

2. Gilyarovskij V. A. Moskva i moskvichi [Moscow and Muscovites]. M.: AST, 2017. 496 s. [In Russian]

3. GAVO. F. I-21. Op. 1. D. 522. [In Russian]

4. Astaf'ev P. E. Nacional'nost' i obshchechelovecheskie zadachi (k russkoj narodnoj psihologii) [ Nationality and universal tasks (to Russian folk psychology)] // Voprosy filosofii. 1996. № 12. S. 84-102. [In Russian]

5. Simonova S. A. Esteticheskij rigorizm ili social'noe alibi iskusstva [Aesthetic rigorism or social alibi of art] // Vestnik Tomskogo universiteta. Ser. Gumanitarnye nauki. 2008. № 310. S. 56-61. [In Russian]

6. GAVO. F. I-21. Op. 1. D. 382. L. 4. [In Russian]

7. GAVO. F. I-21. Op. 1. D. 522. L. 3 ob.; 5 ob. [In Russian]

8. GAVO. F. I-21. Op. 1. D. 1028. [In Russian]

9. Simonova S. A. Osobennosti absolyutizacii dobra v russkoj kul'ture [Features of the absolutization of good in Russian culture] // Social'no-gumanitarnye znaniya. 2008. № 3. S. 332-339. [In Russian]

10. Fetisov V. P. Filosofiya morali: toska po russkomu aristokratizmu [Philosophy of morality: longing for Russian aristocracy]. Voronezh: Kvadrat, 1995. 119 s. [In Russian]

Статья поступила в редакичию 09.07.2020 Статья допущена к публикации 15.10.2020

The article was received by the editorial staff 09.07.2020 The article is approved for publication 15.10.2020 